\title{
The prevalence of multimorbidity and its association with physical activity and sleep duration in middle aged and elderly adults: a longitudinal analysis from China
}

Li He${ }^{1}$, Stuart J. H. Biddle², John Tayu Lee ${ }^{3,4}$, Nadila Duolikun ${ }^{5}$, Lin Zhang ${ }^{6,7}$, Zijie Wang ${ }^{1}$ and Yang Zhao ${ }^{5,8^{*}}$ (D)

\begin{abstract}
Background: Preventing chronic disease is important in health policy in countries with significantly ageing populations. This study aims to examine the prevalence of chronic disease multimorbidity and its association with physical activity and sleep duration; and to understand whether physical activity modifies associations between sleep duration and multimorbidity.

Methods: We utilized longitudinal data of a nationally-representative sample from the China Health and Retirement Longitudinal Study (in year 2011 and 2015; N=5321; 54.7\% female; age $\geq 45$ years old). Fourteen chronic diseases were used to measure multimorbidity (ten self-reported, and four by blood test). Participants were grouped into high, moderate, and low level based on self-reported frequencies and durations of physical activity with different intensities for at least $10 \mathrm{~min}$ at a time in a usual week. Poor and good sleepers were categorized according to average hours of actual sleep at each night during the past month. Panel data method of random-effects logistic regression model was applied to estimate the association of physical activity and sleep with multimorbidity, adjusting for social-demographic and behavioural confounders.
\end{abstract}

Results: From 2011 to 2015, the prevalence of multimorbidity increased from 52.2 to 62.8\%. In 2015, the proportion of participants engaging in high, moderate, and low level of physical activity was $30.3,24.4$ and $45.3 \%$, respectively, and $63.6 \%$ of adults had good sleep. For both genders, compared with good sleep, poor sleep was associated with higher odds of multimorbidity ( $\mathrm{OR}=1.527,95 \% \mathrm{Cl}: 1.277,1.825)$. Compared to the high-level group, participants with a low level of physical activity were significantly more likely to have multimorbidity (OR $=1.457,95 \% \mathrm{Cl}: 1.277$, 1.825), but associations were stronger among women. The relative excess risk due to interaction between poor sleep and moderate or low physical activity was positive but non-significant on multimorbidity.

Conclusions: The burden of multimorbidity was high in China. Low physical activity and poor sleep was independently and significantly associated with a higher likelihood of multimorbidity in women and both genders, separately. Physical activity could modify the association between sleep and multimorbidity.

Keywords: Multimorbidity, Physical activity, Sleep, Adults, China

\footnotetext{
* Correspondence: Wzhao@georgeinstitute.org.cn

${ }^{5}$ Women \& Child Health Program, GIC, The George Institute for Global Health at Peking University Health Science Center, Beijing, China

${ }^{8} \mathrm{WHO}$ Collaborating Centre on Implementation Research for Prevention and Control of Noncommunicable Diseases, Melbourne, VIC, Australia

Full list of author information is available at the end of the article
}

C C The Author(s). 2021 Open Access This article is licensed under a Creative Commons Attribution 4.0 International License, which permits use, sharing, adaptation, distribution and reproduction in any medium or format, as long as you give appropriate credit to the original author(s) and the source, provide a link to the Creative Commons licence, and indicate if changes were made. The images or other third party material in this article are included in the article's Creative Commons licence, unless indicated otherwise in a credit line to the material. If material is not included in the article's Creative Commons licence and your intended use is not permitted by statutory regulation or exceeds the permitted use, you will need to obtain permission directly from the copyright holder. To view a copy of this licence, visit http://creativecommons.org/licenses/by/4.0/. The Creative Commons Public Domain Dedication waiver (http://creativecommons.org/publicdomain/zero/1.0/) applies to the data made available in this article, unless otherwise stated in a credit line to the data. 


\section{Background}

Meeting the recommended physical activity level and having enough sleep are well known to be as the main behavioural strategies for the management of some specific non-communicable diseases, such as obesity, diabetes, cancers and depression [1, 2]. However, whether and to what extent the benefits of physical activity and sleep duration on preventing or predicting the multimorbidity are relatively unknown in China.

Multimorbidity is defined as two or more chronic diseases co-existing in an individual [3]. Despite the inconsistency in measurement, the literature shows that multimorbidity is highly prevalent among middle-aged and older adults, ranging from 30 to $95 \%$ across age groups and countries [4]. In China, multimorbidity is common among middle-aged and older adults, with a prevalence of nearly $50 \%[5,6]$. Compared with single chronic conditions, multimorbidity has been associated with more outpatient visits, longer hospital stays, increased health care costs $[7,8]$, more mental complaints or disorders $[9,10]$, lower quality of life [11], and increased risk of mortality [12, 13]. Accordingly, preventing the rising prevalence of multimorbidity has become an important clinical and public health challenge in China as well as other countries.

Several longitudinal studies have assessed associations of physical activity with multimorbidity, but they were largely conducted in high-income countries such as Canada, the United Kingdom (UK), Germany, and other European countries, where the results were mixed and ranged from an inverse association/effect to none on multimorbidity [14-22]. For example, in a longitudinal study, compared to the physically inactive group, the odds of multimorbidity were reduced by $39 \%$ in the moderate physical activity group in an older English population [15]. In contrast, in another UK study, being physically inactive $(<2.5 \mathrm{~h}$ /week of moderate or vigorous physical activity) was not found to be a significant risk factor for transitioning from one disease to the multimorbidity in a cohort of 8270 middle-aged adults [20]. Only one cross-sectional study using data from 46 lowmiddle income countries included a small sample from China, and 3393 Chinese adults aged $\geq 18$ years with chronic conditions and multimorbidity were found to be significantly less physically active (especially older adults, $<150 \mathrm{~min} /$ week) [23]. The relationship between physical activity and multimorbidity in Chinese adults should be explored further using a nationally representative sample, with a particular longitudinal design.

Previous studies have also assessed combined associations of physical activity and other lifestyle factors (e.g., sedentary behaviour, smoking, alcohol consumption and/or diet) with multimorbidity using analysis of interaction or composite index [16, 20, 24-26]. For example,
Freisling et al. computed a composite healthy lifestyle index using physical activity, smoking, alcohol intake, body mass index, and diet, in a prospective cohort study. A higher healthy lifestyle index score was strongly inversely associated with multimorbidity among 291,778 adults from seven European countries [16]. However, few studies have examined how physical activity and sleep duration influence multimorbidity. Significant associations were observed between sleep duration and multimorbidity in Germany, Canada, and Luxembourg [27-29], but no study examined sleep duration and multimorbidity in China. In a sample of 3176 elderly Chinese community adults aged 60 years old and older [30], significantly higher proportions of multimorbidity (e.g., arrhythmia, hypertension, cerebral haemorrhage, migraine, and hyperlipidaemia) were observed in people with insomnia than in people without insomnia. Still, it is unclear whether physical activity can attenuate or enhance the association of sleep duration with multimorbidity, or vice versa. Since sleep may be interrelated with physical activity, the sleep-multimorbidity relationship may differ among people with different levels of activity [31, 32]. The associations among physical activity, sleep duration and the risk of multimorbidity should also be determined and managed to prevent multimorbidity.

Collectively, to address the above limitations, the present study aimed to a) examine the prevalence of chronic disease multimorbidity and its association with physical activity and sleep duration; and b) understand whether physical activity can attenuate or amplify the association of sleep duration with multimorbidity after adjusting for other behavioural risk factors. Given the possible behavioural differences varying by gender [33], subgroup analysis by gender was conducted in the present study.

\section{Methods}

\section{Sample and data}

This study used longitudinal data from two waves of the China Health and Retirement Longitudinal Study (CHARLS) conducted in 2011 and 2015. The CHARLS is a biennial survey conducted by the National School of Development at Peking University, that aimed to be representative of Chinese residents aged 45 years and older. The data were collected via a survey in which four-stage, stratified, cluster sampling was used to randomly select eligible individuals [34]. Briefly, 150 areas in China (counties) were first selected proportional to population size. Then, three villages/communities were selected from each county as primary sampling units (PSUs). In each of the 450 PSUs, 80 households were randomly selected, with 24 for investigation. If the household had persons aged 45 years and over, one of them was randomly chosen, and both respondents and their spouses were interviewed using structured questionnaires. A 
detailed description of the survey objectives and methods has been reported elsewhere [34].

A total of 17,708 participants from 10,257 households were interviewed in person using questionnaires; the overall household response rate was $80.5 \%$. Ongoing follow-up surveys were conducted every two years. For this study, we used longitudinal data based on the baseline in 2011 and the second follow-up wave of the CHARLS in 2015. Given that physical activity items were presented only to half of the sample of households randomly selected, after removing respondents aged below 45 years and individuals with missing values of dependent or independent variables, our final sample had 5321 respondents (the sample flowchart is presented in Fig. S1). In total, 10,642 persontimes were included for the panel data analyses.

\section{Measures}

\section{Chronic diseases multimorbidity}

In this study, multimorbidity was defined as the presence of two or more chronic diseases [35]. A total of fourteen chronic diseases were used to measure physical multimorbidity. Hypertension, diabetes, dyslipidaemia, and hyperuricemia were measured by biomarkers or blood test information. Ten diagnosed chronic diseases were self-reported (heart disease, stroke, cancer, chronic lung disease, digestive disease, liver disease, kidney disease, memory-related disease [such as dementia, brain atrophy and/or Parkinson's disease], arthritis and asthma). The combination of fourteen measured and reported diseases that were used to count the number of chronic diseases for each participant, and those individuals with occurrence of two or more chronic conditions would be identified to have multimorbidity.

In the CHARLS, each respondent's systolic blood pressure (SBP) and diastolic blood pressure (DBP) were recorded three times by a trained nurse using a HEM7112 electronic monitor (OMRON, Tokyo, Japan). Diagnosed hypertension was defined as $\mathrm{SBP} \geq 140 \mathrm{mmHg}$ and/ or $\mathrm{DBP} \geq 90 \mathrm{mmHg}$, and/or being on anti-hypertensive medication for raised blood pressure [36]. Diabetes was defined by 1) a fasting plasma glucose level of $\geq 126 \mathrm{mg} / \mathrm{dL}$ (7.0 mmol/L); and/or 2) HbA1c concentration of $\geq 6.5 \%$; and/or 3) being insulin treatment and/or taking medication for raised blood sugar [37]. Dyslipidaemia was defined by 1 ) total cholesterol (TC) $\geq 240 \mathrm{mg} / \mathrm{dL}(6.22 \mathrm{mmol} / \mathrm{L})$; and/or 2) low-density lipoprotein cholesterol (LDL-C) $\geq$ $160 \mathrm{mg} / \mathrm{dL}$ ( $4.14 \mathrm{mmol} / \mathrm{L})$; and/or 2) high-density lipoprotein cholesterol (HDL-C) $<40 \mathrm{mg} / \mathrm{dL}(1.04 \mathrm{mmol} / \mathrm{L})$; and/ or 2$)$ triglyceride (TG) $\geq 200 \mathrm{mg} / \mathrm{dL}(2.26 \mathrm{mmol} / \mathrm{L})$; and/or 2) taking anti-dyslipidaemia medication [38].

\section{Physical activity level}

The level of physical activity was measured by a modified version of the International Physical Activity Questionnaire
(IPAQ) [39], which was determined by the frequency and duration of physical activities at different intensities. In the CHARLS, participants were asked to recall vigorous, moderate, and light physical activities that they did for at least $10 \mathrm{~min}$ at a time in a usual week. If they performed any vigorous, moderate and light physical activities for at least 10 min continuously at a time, they were further asked to report the frequency and duration. For example, "during a usual week, on how many days did you do vigorous physical activities for at least 10 minutes?" The responses ranged from 1 to 7 days. In addition, for the question "How much time did you usually spend doing vigorous physical activates on one of those days?", the response options were $<30 \mathrm{~min}$, $30 \mathrm{~min}$ to $2 \mathrm{~h}, 2 \mathrm{~h}$ to $4 \mathrm{~h}$, and $\geq 4 \mathrm{~h}$. Besides, participants were requested to recall time they spent walking in a usual week. This includes at work and at home, walking to travel from place to place, and any other walking that they might do solely for recreation, sport, exercise, or leisure. Responses were as the same as other activities.

For analysis, the criterion for classification as "highlevel' was vigorous-intensity activity on at least 3 days of at least $30 \mathrm{~min}$ per day, which was developed to describe higher levels of participation in physical activities. The pattern of activity to be classified as 'moderate-level' was either of the following criteria: a) 3 or more days of vigorous-intensity activity of at least $10 \mathrm{~min}$ per day (less than 30 min per day; 'at least 20 minutes per day' in the IPAQ), or b) 5 or more days of moderate-intensity activity and/or walking of at least $30 \mathrm{~min}$ per day. Individuals who did not meet the criteria for categories 'high' or 'moderate' were considered to have a 'low' physical activity level [40].

\section{Sleep duration}

Participants were asked to report average hours of actual sleep they get at each night during the past month. In this study, the sleep duration was not inclusive of naps. Response options ranged from 0 to $24 \mathrm{~h}$. Based on the recommended sleep time [41], responses were recoded to "poor sleep" and "good sleep [7-9 hours]". Poor sleepers were defined as those who did not meet the recommended sleep duration, either less than $7 \mathrm{~h}$ per day or more than $9 \mathrm{~h}$.

\section{Covariates}

We included the following variables as covariates in the main regression analyses: age $(45-54,55-64,65-74$, and 75 and above), gender (male, and female), marital status (married and partnered, and unmarried and others), level of education (pre-primary, primary school, secondary school, and college and above), residence place (rural, and urban), geographical region (east, central, and west), social health insurance (yes, and no), body mass index (BMI) [normal weight (BMI: $18.5-24.9 \mathrm{~kg} / \mathrm{m}^{2}$ ), 
low-weight $\left(<18.5 \mathrm{~kg} / \mathrm{m}^{2}\right)$, overweight (BMI: $25-29.9 \mathrm{~kg} /$ $\mathrm{m}^{2}$ ), obesity (BMI: $\geq 30 \mathrm{~kg} / \mathrm{m}^{2}$ )], depression (yes, and no), smoking cigarettes, and drinking alcohol.

In this study, depression was assessed by the 10-item Centre for Epidemiologic Studies Depression Scale (CES-D) [42]. The CES-D is a validated mental health assessment tool for older people in China [42]. Details of the CESD-10 were described elsewhere [43]. The scores of the CESD-10 ranged from 0 to 30. In this study, participants who had a CESD-10 score of $\geq 10$ were defined as having depressive symptoms. A binary variable of depression was constructed by defining an individual whose CESD-10 score was equal to or above 10 as having depression symptoms.

Regarding smoking, the number of cigarettes smoked per day was calculated based on the responses of the following items: "Have you ever chewed tobacco, smoked a pipe, smoked self-rolled cigarettes, or smoked cigarettes/ cigars?" The answer was Yes or No. If yes, participants were then asked to report "Do you still have the habit or have you totally quit?" and then "In one day about how many cigarettes do/did you consume". For drinking behaviour, the frequency of any type of alcohol (i.e., beer, wine, or liquor) that respondents most frequently drank during the last year was counted. The frequency of drinking was defined as: (1) none or no drinking, (2) once a month, (3) 2 to 3 days a month, (4) once a week, (5) 2 to 3 days a week, (6) 4 to 6 days a week, (7) daily, (8) twice a day, and (9) more than twice a day.

\section{Statistical analysis}

We used the chi-square test to explore the sociodemographic disparity in the prevalence of multimorbidity. The panel data approach of a random effects logistic regression model was applied to estimate the independent association of physical activity and sleep with multimorbidity. We tested for multicollinearity for covariates adjusted for in our analysis. The multicollinearity diagnostic (variance inflation factor) values were all less than five, indicating that the assumption of reasonable independence among predictor variables was met [44]. The adjusted odds ratio (OR) and $95 \%$ confidence intervals (CIs) were reported in regression models. We also performed multivariable regressions to examine associations of sleep duration with multimorbidity stratified by gender and physical activity groups by adjusting sociodemographic variables excluding gender and/or physical activity group. In addition, measures of effect modification on both additive (e.g. the relative excess risk due to interaction, RERI) and multiplicative scales with CIs were presented $[45,46]$. The tests for additive interaction would be useful for targeting subpopulations for which the intervention is most effective [47]. All analyses were weighted to account for the complex, multi-stage design, and non-response in the CHARLS data. The statistical analyses in this study were conducted using Stata software 16.0 (Stata Corp., College Station, Texas). P values $<0.05$ were considered statistically significant.

\section{Results}

We analysed data from 5321 respondents. Table 1 presents the respondents' socioeconomic and demographic characteristics. In 2015, older adults ( $\geq 65$ years) accounted for $35.8 \%$ of the total participants. There was a slightly higher percentage of female respondents $(54.8 \%)$ than male respondents. Most of the respondents were married (85.2\%) and resided in rural areas (57.0\%). Only $35.6 \%$ of the respondents had attained a level of education higher than primary school. Moreover, the proportions of overweight and obese individuals in 2015 were 28.5 and 4.6\%, respectively. From 2011 to 2015, the proportion of respondents achieving high-level physical activity and moderate-level physical activity decreased slightly from 32.4 and $25.9 \%$ to 30.3 and $24.4 \%$, respectively. A total of 67.6 and $63.6 \%$ of respondents met the recommended sleep durations in 2011 and 2015, respectively. The prevalence of multimorbidity was shown to have increased from $52.2 \%$ in 2011 to $62.8 \%$ in 2015 .

Table 2 represents the prevalence of multimorbidity ( $\geq 2$ chronic diseases) by physical activity and sleep categories, stratified by gender. Chi-square analysis demonstrated that, for both men and women, there were differences in the distribution of multimorbidity for sleep and physical activity categories. For example, the prevalence of multimorbidity was higher in the low-level physical activity group (55.1\%) than in the moderatelevel (51.4\%) and high-level physical activity group (49.2\%) in 2011; the prevalence was also higher in the poor sleep group (61.2\%) than in the good sleep group (48.0\%). Similar patterns were found in 2015 in China. There were gender differences in multimorbidity burdens, with a higher prevalence of multimorbidity in females experiencing low-level physical activity (66.8\%) and poor sleep $(71.3 \%)$ than in males having low-level physical activity (61.8\%) and poor sleep (63.3\%) in 2015.

Table 3 depicts the results of the multivariable logistic regression analysis with covariate adjustment. Compared with participants reporting high levels of physical activity, moderate physical activity $(\mathrm{OR}=1.266,95 \% \mathrm{CI}$ : $0.990,1.619)$ and low physical activity (OR $=1.457,95 \%$ CI: $1.156,1.836)$ was independently associated with higher risk of multimorbidity, respectively. While the higher odds of multimorbidity for women with a low level of physical activity (OR $=1.560,95 \% \mathrm{CI}$ : 1.114 , 2.186) compared with the high level, no significant association was found between physical activity level and multimorbidity in men. Further, it was observed that poor sleep was significantly associated with higher 
Table 1 Characteristics of sample in 2011 and 2015

\begin{tabular}{|c|c|c|c|c|c|c|}
\hline & & 2011 & & & 2015 & \\
\hline & $\mathbf{N}$ & Unweighted \% & Weighted \% & $\mathbf{N}$ & Unweighted \% & Weighted \% \\
\hline Total & 5321 & 100.0 & 100.0 & 5321 & 100.0 & 100.0 \\
\hline Age (year) & & & & & & \\
\hline $45-54$ & 2073 & 39.0 & 40.2 & 1350 & 25.4 & 26.1 \\
\hline $55-64$ & 2055 & 38.6 & 37.1 & 2074 & 39.0 & 38.1 \\
\hline $65-74$ & 946 & 17.8 & 17.6 & 1387 & 26.1 & 25.3 \\
\hline 75 and above & 247 & 4.6 & 5.1 & 510 & 9.6 & 10.5 \\
\hline Gender & & & & & & \\
\hline Male & 2411 & 45.3 & 45.0 & 2411 & 45.3 & 45.2 \\
\hline Female & 2910 & 54.7 & 55.0 & 2910 & 54.7 & 54.8 \\
\hline Marital status & & & & & & \\
\hline Married and partnered & 4758 & 89.4 & 88.2 & 4594 & 86.3 & 85.2 \\
\hline Unmarried and other & 563 & 10.6 & 11.8 & 727 & 13.7 & 14.8 \\
\hline Education status & & & & & & \\
\hline Pre-primary & 2399 & 45.1 & 42.9 & 2399 & 45.1 & 42.3 \\
\hline Primary school & 1202 & 22.6 & 22.5 & 1202 & 22.6 & 22.1 \\
\hline Secondary school & 1126 & 21.2 & 22.5 & 1126 & 21.2 & 22.9 \\
\hline College and above & 594 & 11.2 & 12.0 & 594 & 11.2 & 12.7 \\
\hline Residence place & & & & & & \\
\hline Urban & 1950 & 36.7 & 42.3 & 1950 & 36.7 & 43.0 \\
\hline Rural & 3371 & 63.4 & 57.7 & 3371 & 63.4 & 57.0 \\
\hline Region & & & & & & \\
\hline East & 2042 & 38.4 & 40.8 & 2042 & 38.4 & 40.4 \\
\hline Central & 1934 & 36.4 & 34.2 & 1934 & 36.4 & 35.7 \\
\hline West & 1345 & 25.3 & 25.1 & 1345 & 25.3 & 24.0 \\
\hline Social health insurance & & & & & & \\
\hline No & 352 & 6.6 & 6.6 & 496 & 9.3 & 9.5 \\
\hline Yes & 4969 & 93.4 & 93.4 & 4825 & 90.7 & 90.5 \\
\hline BMI & & & & & & \\
\hline Normal & 3358 & 63.1 & 63.5 & 3211 & 60.4 & 60.8 \\
\hline Underweight & 292 & 5.5 & 5.5 & 324 & 6.1 & 6.1 \\
\hline Overweight & 1431 & 26.9 & 26.5 & 1531 & 28.8 & 28.5 \\
\hline Obesity & 240 & 4.5 & 4.6 & 255 & 4.8 & 4.6 \\
\hline Depression & & & & & & \\
\hline No & 3386 & 63.6 & 64.9 & 3465 & 65.1 & 66.3 \\
\hline Yes & 1935 & 36.4 & 35.1 & 1856 & 34.9 & 33.7 \\
\hline Physical activity & & & & & & \\
\hline Low & 2082 & 39.1 & 41.7 & 2253 & 42.3 & 45.3 \\
\hline Moderate & 1381 & 26.0 & 25.9 & 1336 & 25.1 & 24.4 \\
\hline High & 1858 & 34.9 & 32.4 & 1732 & 32.6 & 30.3 \\
\hline Sleep duration & & & & & & \\
\hline Poor $(<7 \mathrm{~h}$ or $>9 \mathrm{~h})$ & 1746 & 32.8 & 32.4 & 1978 & 37.2 & 36.4 \\
\hline Good [7 h-9 h] & 3575 & 67.2 & 67.6 & 3343 & 62.8 & 63.6 \\
\hline
\end{tabular}


Table 1 Characteristics of sample in 2011 and 2015 (Continued)

\begin{tabular}{|c|c|c|c|c|c|c|}
\hline & & 2011 & & & 2015 & \\
\hline & $\mathrm{N}$ & Unweighted \% & Weighted \% & $\mathrm{N}$ & Unweighted \% & Weighted \% \\
\hline Multim & & & & & & \\
\hline No & 2464 & 46.3 & 47.8 & 1912 & 35.9 & 37.2 \\
\hline Yes & 2857 & 53.7 & 52.2 & 3409 & 64.1 & 62.8 \\
\hline
\end{tabular}

Note: The values are weighted percentages unless otherwise indicated. BMI, Body Mass Index. h, hours

multimorbidity in both genders (women: $\mathrm{OR}=1.614$, 95\% CI: 1.263, 2.063; men: OR = 1.428, 95\% CI: 1.099 , 1.855).

The associations of poor sleep with multimorbidity, stratified by gender and physical activity categories, are further illustrated in Fig. 1. After adjustment for covariates, compared with good sleep, the odds of multimorbidity for poor sleepers was 1.511 in high physical activity group (95\% CI: 1.081, 2.112), 1.832 in moderate physical activity group (95\% CI: $1.257,2.671$ ), and 1.552 in low physical activity group (95\% CI: 1.175, 2.050). Among women, compared with good sleep, the odds for poor sleepers having multimorbidity was 1.736, 1.928 and 1.598 in the high-level (95\% CI:1.044, 2.887), moderate-level (95\% CI: 1.158, 3.211), and low level of physical activity group (95\% CI:1.111, 2.298), respectively. For men who were sleep well or not, physical activity was not significantly associated with multimorbidity.

We first examined the effect modification of physical activity on sleep and multimorbidity (Table 4). Overall, highest risk of multimorbidity was found in participants with poor sleep and low-level of physical activity (OR = 2.181, 95\% CI:1.903-2.499), where high physical activity and good sleep was as the reference group giving the

Table 2 Prevalence of multimorbidity stratified by gender, physical activity and sleep duration in 2011 and 2015

\begin{tabular}{|c|c|c|c|c|c|c|}
\hline & \multicolumn{3}{|c|}{2011} & \multicolumn{3}{|c|}{2015} \\
\hline & $\%$ & \multicolumn{2}{|l|}{$95 \% \mathrm{Cl}$} & $\%$ & \multicolumn{2}{|c|}{$95 \% \mathrm{Cl}$} \\
\hline \multicolumn{7}{|l|}{ Overall } \\
\hline \multicolumn{7}{|l|}{ Physical activity } \\
\hline Low & 55.1 & 52.1 & 58.0 & 64.7 & 61.9 & 67.3 \\
\hline Moderate & 51.4 & 48.4 & 54.5 & 61.9 & 58.8 & 64.9 \\
\hline High & 49.2 & 46.7 & 51.8 & 60.9 & 58.3 & 63.5 \\
\hline \multicolumn{7}{|l|}{ Sleep duration } \\
\hline Poor $(<7 \mathrm{~h}$ or $>9 \mathrm{~h})$ & 61.2 & 58.5 & 63.8 & 67.9 & 65.0 & 70.7 \\
\hline Good [7 h-9 h] & 48.0 & 45.9 & 50.0 & 59.9 & 57.9 & 61.9 \\
\hline \multicolumn{7}{|l|}{ Males } \\
\hline \multicolumn{7}{|l|}{ Physical activity } \\
\hline Low & 52.6 & 47.9 & 57.3 & 61.8 & 57.2 & 66.2 \\
\hline Moderate & 53.7 & 49.1 & 58.3 & 60.5 & 55.7 & 65.0 \\
\hline High & 47.3 & 43.9 & 50.8 & 59.5 & 55.9 & 63.1 \\
\hline \multicolumn{7}{|l|}{ Sleep duration } \\
\hline Poor $(<7 \mathrm{~h}$ or $>9 \mathrm{~h})$ & 57.9 & 53.6 & 62.1 & 63.3 & 58.0 & 68.4 \\
\hline Good [7 h-9 h] & 47.7 & 44.8 & 50.7 & 59.4 & 56.6 & 62.1 \\
\hline \multicolumn{7}{|l|}{ Females } \\
\hline \multicolumn{7}{|l|}{ Physical activity } \\
\hline Low & 56.8 & 52.9 & 60.6 & 66.8 & 63.5 & 69.9 \\
\hline Moderate & 50.0 & 46.0 & 54.0 & 62.8 & 58.6 & 66.7 \\
\hline High & 51.5 & 47.7 & 55.3 & 62.5 & 58.7 & 66.1 \\
\hline \multicolumn{7}{|l|}{ Sleep duration } \\
\hline Poor $(<7 \mathrm{~h}$ or $>9 \mathrm{~h})$ & 63.6 & 60.1 & 66.9 & 71.3 & 68.2 & 74.1 \\
\hline Good [7 h-9h] & 48.2 & 45.3 & 51.0 & 60.4 & 57.5 & 63.3 \\
\hline
\end{tabular}


Table 3 The relationships between multimorbidity, and physical activity and sleep duration

\begin{tabular}{|c|c|c|c|c|c|c|c|c|c|c|c|c|}
\hline \multirow[t]{2}{*}{ Variables } & \multicolumn{4}{|c|}{ Total participants } & \multicolumn{4}{|c|}{ Males } & \multicolumn{4}{|c|}{ Females } \\
\hline & $\overline{\mathrm{OR}}$ & $P$ value & \multicolumn{2}{|c|}{$95 \% \mathrm{Cl}$} & $\overline{\mathrm{OR}}$ & $P$ value & \multicolumn{2}{|c|}{$95 \% \mathrm{Cl}$} & $\overline{\mathrm{OR}}$ & $P$ value & \multicolumn{2}{|c|}{$95 \% \mathrm{Cl}$} \\
\hline \multicolumn{13}{|c|}{ Physical activity (Ref. High) } \\
\hline Moderate & 1.266 & 0.061 & 0.990 & 1.619 & 1.376 & 0.072 & 0.972 & 1.950 & 1.203 & 0.301 & 0.848 & 1.707 \\
\hline Low & 1.457 & 0.001 & 1.156 & 1.836 & 1.349 & 0.065 & 0.982 & 1.853 & 1.560 & 0.010 & 1.114 & 2.186 \\
\hline \multicolumn{13}{|c|}{ Sleep duration (Ref. Good) } \\
\hline Poor $(<7 \mathrm{~h}$ or $>9 \mathrm{~h})$ & 1.527 & $<0.001$ & 1.277 & 1.825 & 1.428 & 0.008 & 1.099 & 1.855 & 1.614 & $<0.001$ & 1.263 & 2.063 \\
\hline \multicolumn{13}{|l|}{ Survey year (Ref. 2011) } \\
\hline 2015 & 2.269 & $<0.001$ & 1.980 & 2.601 & 2.165 & $<0.001$ & 1.783 & 2.628 & 2.378 & $<0.001$ & 1.962 & 2.882 \\
\hline \multicolumn{13}{|l|}{ Gender (Ref. Male) } \\
\hline Female & 0.792 & 0.102 & 0.599 & 1.048 & - & - & - & - & - & - & - & - \\
\hline \multicolumn{13}{|l|}{ Age (Ref. 45-54) } \\
\hline $55-64$ & 2.530 & $<0.001$ & 2.010 & 3.186 & 2.123 & $<0.001$ & 1.515 & 2.976 & 2.835 & $<0.001$ & 2.065 & 3.893 \\
\hline $65-74$ & 4.690 & $<0.001$ & 3.480 & 6.321 & 3.460 & $<0.001$ & 2.276 & 5.259 & 6.029 & $<0.001$ & 3.927 & 9.257 \\
\hline 75 and above & 5.681 & $<0.001$ & 3.613 & 8.933 & 3.960 & $<0.001$ & 2.169 & 7.232 & 8.127 & $<0.001$ & 4.077 & 16.198 \\
\hline \multicolumn{13}{|c|}{ Marital status (Ref. Married and partnered) } \\
\hline Unmarried and other & 0.862 & 0.369 & 0.623 & 1.193 & 0.919 & 0.740 & 0.560 & 1.510 & 0.761 & 0.223 & 0.491 & 1.181 \\
\hline \multicolumn{13}{|c|}{ Education status (Ref. Pre-primary) } \\
\hline Primary school & 1.011 & 0.942 & 0.750 & 1.364 & 1.126 & 0.581 & 0.738 & 1.719 & 0.929 & 0.738 & 0.603 & 1.431 \\
\hline Secondary school & 0.684 & 0.021 & 0.495 & 0.944 & 0.718 & 0.142 & 0.462 & 1.117 & 0.644 & 0.073 & 0.398 & 1.042 \\
\hline College \& above & 0.687 & 0.071 & 0.457 & 1.033 & 0.706 & 0.194 & 0.417 & 1.194 & 0.661 & 0.216 & 0.343 & 1.274 \\
\hline \multicolumn{13}{|c|}{ Residence place (Ref. Urban) } \\
\hline Rural & 1.130 & 0.331 & 0.883 & 1.445 & 1.224 & 0.251 & 0.867 & 1.728 & 1.046 & 0.804 & 0.735 & 1.487 \\
\hline \multicolumn{13}{|l|}{ Region (Ref. East) } \\
\hline Central & 2.364 & $<0.001$ & 1.816 & 3.077 & 2.382 & $<0.001$ & 1.646 & 3.446 & 2.382 & $<0.001$ & 1.636 & 3.468 \\
\hline West & 2.815 & $<0.001$ & 2.089 & 3.792 & 2.359 & $<0.001$ & 1.554 & 3.580 & 3.352 & $<0.001$ & 2.191 & 5.130 \\
\hline \multicolumn{13}{|c|}{ Social health insurance (Ref. No) } \\
\hline Yes & 1.461 & 0.011 & 1.091 & 1.957 & 1.516 & 0.055 & 0.992 & 2.316 & 1.418 & 0.091 & 0.946 & 2.125 \\
\hline \multicolumn{13}{|l|}{ BMI (Ref. Normal) } \\
\hline Underweight & 0.896 & 0.606 & 0.589 & 1.361 & 1.010 & 0.972 & 0.573 & 1.781 & 0.786 & 0.444 & 0.425 & 1.456 \\
\hline Overweight & 3.457 & $<0.001$ & 2.725 & 4.387 & 3.696 & $<0.001$ & 2.580 & 5.294 & 3.328 & $<0.001$ & 2.417 & 4.582 \\
\hline Obesity & 4.725 & $<0.001$ & 2.901 & 7.696 & 4.554 & $<0.001$ & 2.004 & 10.351 & 4.812 & $<0.001$ & 2.596 & 8.922 \\
\hline Smoking cigarettes & 0.987 & 0.037 & 0.975 & 0.999 & 0.985 & 0.017 & 0.973 & 0.997 & 1.000 & 0.996 & 0.955 & 1.048 \\
\hline Drinking alcohol & 0.927 & 0.001 & 0.885 & 0.970 & 0.923 & 0.001 & 0.879 & 0.969 & 0.956 & 0.430 & 0.855 & 1.069 \\
\hline \multicolumn{13}{|l|}{ Depression (Ref. No) } \\
\hline Yes & 2.580 & $<0.001$ & 2.137 & 3.114 & 2.395 & $<0.001$ & 1.798 & 3.190 & 2.745 & $<0.001$ & 2.135 & 3.530 \\
\hline
\end{tabular}

Note: Analyses were adjusted for survey year, age, educational level, marital status, living place, household income, health insurance, Body Mass Index (BMI), smoking cigarettes, drinking alcohol, depression and mutually adjusted for physical activity and sleep. Ref. reference group. $h$ hours

lowest risk of multimorbidity. The relative excess risk due to interaction of poor sleep and physical activity on multimorbidity was presented by RERI (for moderate physical activity: $0.123,95 \% \mathrm{CI}:-0.264,0.510$; for moderate physical activity: $0.298,95 \%$ CI: $-0.099,0.695)$. It showed that there was positive effect modification of sleep duration across strata of physical activity on an additive scale. Moreover, no statistically significant multiplicative interaction between sleep duration and physical activity was detected (Additional file Table S2).

\section{Discussion}

This study first examines the prevalence and association of multimorbidity with physical activity and sleep using nationally representative data of Chinese adults. In line with previous studies [5-7], multimorbidity was highly 


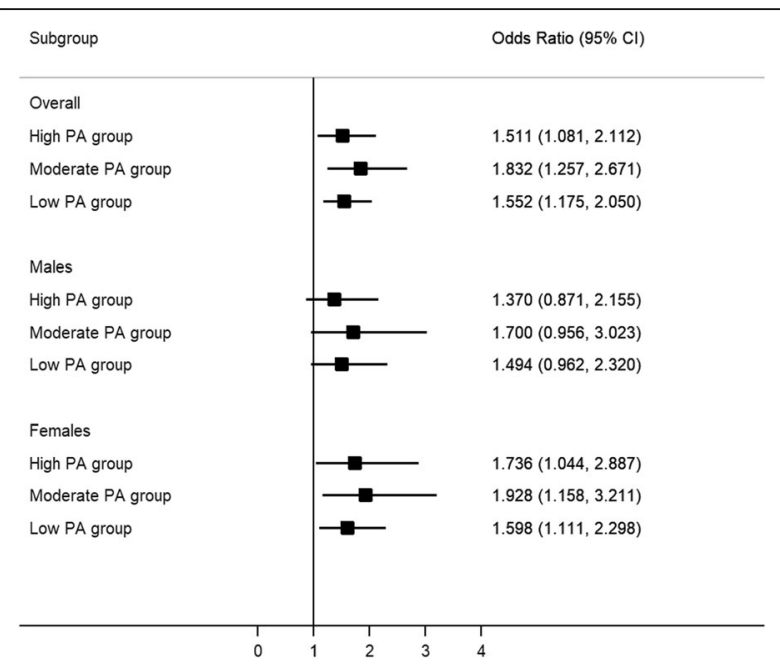

Fig. 1 Relationships between poor sleep and multimorbidity stratified by physical activity level and gender. Note: The analyses were adjusted for age, gender, educational level, marital status, living place, household income, health insurance, Body Mass Index (BMI), smoking cigarettes, drinking alcohol and depression

prevalent in Chinese adults, and the prevalence increased with age. Management of multimorbidity, therefore, deserves more attention from health policymakers and health professionals in China.

First, the findings of the present study strengthen the evidence that compared to high-level, low-level physical activity was independently and significantly related to an increased risk of multiple chronic diseases. Increased odds of multimorbidity were also observed in the lower physical activity or physical inactivity group in a Finnish population-based cohort of 25-64-year-old men and women [22], in a cohort of English adults aged $\geq 50$ years $[15,19,25]$, and in women at baseline age of $45-50$ years from the Australian Longitudinal Study on Women's Health [17, 21]. Our findings were largely consistent with the abovementioned studies, but the lack of a significant association between physical activity and multimorbidity in men was new. We want to be cautious interpreting these findings with more research on gender-specific analysis, particularly in men; however, these findings could encourage further efforts to promote physical activity in women.

The second main finding from the current investigation suggested that $7-9 \mathrm{~h}$ of sleep per day might be beneficial for preventing multimorbidity for both men and women. The risk for co-existing multiple chronic diseases has been previously shown to be higher for adults with insomnia in Northern China [30]. The present study extended these observations in a larger sample of Chinese adults and verified that sleep duration was also important for preventing multimorbidity. Compared with $7-8 \mathrm{~h}$ of sleep per day, both shorter and longer sleep durations were associated with higher total and cardiovascular disease mortality [32]. Similarly, increased odds of multimorbidity were observed in 30,011 Canadian, 3833 adults in Germany, and 1508 Luxembourg residents who sleep less than $6 \mathrm{~h}$ in three cross-sectional studies [27-29]. These findings indicated that sleep under the recommended $7 \mathrm{~h}$ per day was deleterious for health.

Although the present study did not examine the long and short duration separately, previous findings suggested that separate associations between long and short sleep duration with multimorbidity were complicated and should be carefully interpreted. For example, while a significant association of short or long sleep with multimorbidity was observed in both German (short: $\leq 5 \mathrm{~h}$, or long $=9 \mathrm{~h}$ ) and Canadian women (short: < $6 \mathrm{~h}$; long: $>8$ $\mathrm{h}$ ), the odds of multimorbidity were different for men who self-reported either short or long sleep duration in the two studies [27, 28]. Furthermore, in Luxembourg, short sleep $(<6 \mathrm{~h})$ duration was associated with the number of chronic conditions, independently of socioeconomic and behavioural characteristics, but long sleep $(>9 \mathrm{~h})$ was not [29]. Given the different definitions of long or short sleep duration, age groups, measures of multimorbidity, or covariates adjusted, inconsistent results were hardly comparable and understandable. This highlights the need for more future research to clarify the associations of sleep and multimorbidity, and the biomechanisms underlying the gender difference.

Last but importantly, our findings go beyond knowledge of this area in one further regard: physical activity modifies the association between poor sleep and multimorbidity. The analysis of additive interaction in the present study indicated that the extent to which the effect of the poor sleep and moderate or low physical activity together exceeded the effect of each considered individually. Also, there were strong indications that estimated effect on the additive scale of poor sleep with moderate or low physical activity was larger than the estimated effect of poor sleep with high physical activity. So, there was positive effect modification of physical activity on an additive scale. These findings had important public health implication in identifying subgroups (e.g. poor sleeper with moderate or low physical activity) would benefit most from the intervention. Previously, the role of physical activity in the relationship between sleep and multimorbidity has not been investigated [26]. This paucity, especially for sparse nationally representative longitudinal studies on this topic, makes it difficult to compare our estimates to the current literature. However, it is important to recognize that significant interactions between sleep duration and physical activity with regard to mortality haven been previously observed [32, 48]. Lower all-cause and cardiovascular mortality were found in women with moderate-to-vigorous 


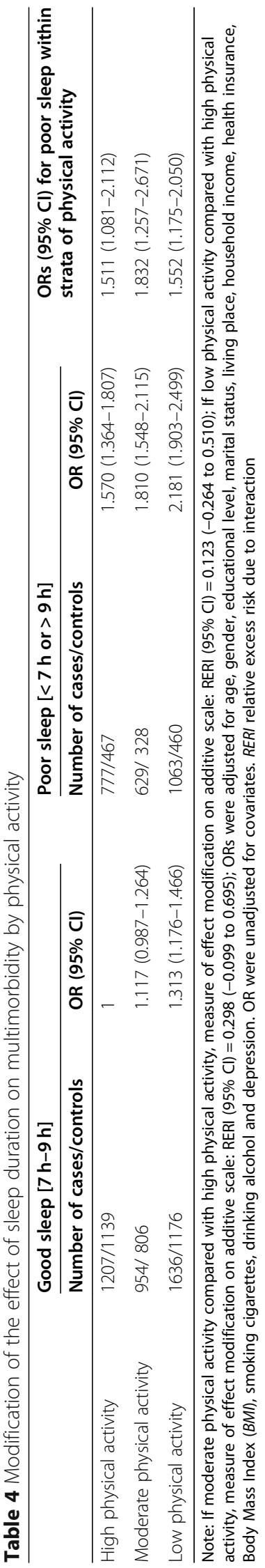


physical activity at least $1 \mathrm{~h}$ per week in all sleep duration groups. Due to the multimorbidity associated with higher mortality, the present finding may be understandable, and reflect the underlying mechanisms of the interaction between sleep and physical activity in relation to mortality. It is therefore crucial to assess multimorbidity status among people with a low level of physical activity and short or long sleep duration in primary care to improve the quality of care for chronic conditions.

\section{Strengths and limitations}

Some strengths and limitations should be acknowledged. The main strength of this study was the nationally representative sample of Chinese adults. Also, this is the first study to use a panel approach to examine associations of physical activity and sleep with multimorbidity in China. In addition, the current study has several limitations.

First, this study examined the prevalence of multimorbidity rather than incidence rate; the use of some self-reported measures of chronic disease (except hypertension, diabetes, dyslipidaemia, and hyperuricemia) or behaviours may underestimate or overestimate their prevalence. Second, the CHARLS did not ask about all chronic diseases typically included in clinical database studies, such as musculoskeletal disorders and thyroid problems [28]. Further studies examining the effect of multimorbidity due to other mental and physical conditions (e.g. Alzheimer's disease, gout, osteoporosis, anxiety, back pain and schizophrenia) are warranted. Third, we examined the effect of behaviour on multimorbidity by simply counting the number of chronic diseases without accounting for the different clusters and severity of chronic diseases. Future research should apply unequal weights according to the type and severity of chronic conditions to explore the impact of behaviours. In addition, this study combined the influence of long and short sleep durations because of the limited number of long sleepers, and the different recommended sleep duration for adults aged 26-64 years old, and adults aged 65 years and older. Age or gender specific analysis of long and short sleep should be considered in future studies with larger samples, separately. Furthermore, causality cannot be established due to the panel analysis; thus, it is unclear whether such behaviours lead to disease or whether increasing numbers of cardiometabolic conditions lead to unhealthy lifestyle behaviours. Last, sleep was assessed just for duration. There are other sleep parameters that are indicative of healthy or unhealthy sleep patterns. There may be other confounding variables that we did not control for, which may influence the results.

\section{Practical implications and future research}

Multimorbidity is becoming progressively common and an increasing burden on public health in China. The present study highlights the need to assess multimorbidity status among women with low levels of physical activity and short sleep or long durations in primary care to improve the quality of care for chronic conditions. Our analyses also provide evidence for the need of monitoring sleep and physical activity behaviour among people without or with single chronic disease, and the need of developing multidisciplinary lifestyle interventions to address poor sleep and inactive lifestyles in China. For this, mobile application (APP), which could get a large scale of adults, is widely recommended, but research to test the efficiency of $\mathrm{m}$-health interventions in assessing and modifying sleep behaviour or combined interventions for physical activity and sleep is limited and warranted in the future [49].

Furthermore, more future research should be conducted to clarify the gender differences in the associations of physical activity and multimorbidity; and the influence of long sleep with larger samples. Finally, our study offers important hypotheses for testing in future prospective cohort or experimental studies. In addition to the duration and frequency of total moderate to vigorous physical activity per week, trials evaluating the dose-response effect of the duration and frequency with different types of physical activity under different intensities are worthy of study.

\section{Conclusions}

The burden of multimorbidity is high in China, particularly among the older population. The present study found that sleep duration and physical activity are independently and significantly associated with multimorbidity. However, in more detail, gender differences were seen regarding the association of physical activity and multimorbidity. Moreover, physical activity could modify the odds of having multimorbidity among poor sleepers.

\section{Abbreviations \\ UK: United Kingdom; CHARLS: China health and retirement longitudinal study; PSUs: Primary sampling units; SBP: Systolic blood pressure; DBP: Diastolic blood pressure; TC: Total cholesterol; LDL-C: Low-density lipoprotein cholesterol; HDL-C: High-density lipoprotein cholesterol; TG: Triglyceride; IPAQ: International physical activity questionnaire; BMI: Body mass index; CES-D: Centre for epidemiologic studies depression scale; OR: Odds ratio; Cl: Confidence intervals; APP: Application; h: Hours; Ref: Reference group; RERI: Relative excess risk due to interaction}

\section{Supplementary Information}

The online version contains supplementary material available at https://doi. org/10.1186/s12966-021-01150-7.

Additional file 1: Figure S1. Flowchart showing the selection of the subjects who were included in the final analysis, 2015.

Additional file 2: Table S1. Characteristics of participants in different physical activity and sleep group.

Additional file 3: Table S2. Joint associations of physical activity and sleep with multimorbidity.

Additional file 4: Table S3. Unadjusted results of regression analyses. 


\section{Acknowledgements}

We gratefully acknowledge the China Health and Retirement Longitudinal Study team for providing data and training in using the datasets. We are grateful to the students who participated in the survey for their cooperation. The authors thank all volunteers and staff involved in this research.

\section{Authors' contributions}

$\mathrm{LH}$ and $Z \mathrm{YY}$ conceived and designed the study. YZ analyzed the data. $\mathrm{LH}$ and ZY interpreted and drafted the manuscript. LH, SJHB, ND, JTL, LZ and ZJW critically revised the first draft. All authors reviewed and had final approval of the submitted and published versions.

\section{Funding}

The National Natural Science Foundation of China Youth Science Foundation (81602869), and the Fundamental Research Funds for the Central Universities (3104221). The funder played no role in the study design, data collection or analysis, the decision to publish, or preparation of the manuscript.

\section{Availability of data and materials}

The datasets generated and/or analyzed during the current study are available in the China Health and Retirement Longitudinal Study repository on reasonable request, http://charls.pku.edu.cn/pages/data/111/zh-cn.html

\section{Declarations}

\section{Ethics approval and consent to participate}

The Biomedical Ethics Review Committee of Peking University approved the China Health and Retirement Longitudinal study, and all interviewees were required to provide informed consent. The ethical approval number was IRB00001052-11015.

\section{Consent for publication}

Not applicable.

\section{Competing interests}

The authors declare that they have no competing interests.

\section{Author details}

${ }^{1}$ College of Physical Education and Sport, Beijing Normal University, Xinjiekouwai Street 19, Haidian District, Beijing 100875, China. ${ }^{2}$ Centre for Health Research, University of Southern Queensland, Springfield, Queensland, Australia. ${ }^{3}$ The Nossal Institute for Global Health, The University of Melbourne, Melbourne, Victoria 3010, Australia. ${ }^{4}$ Public Health Policy Evaluation Unit, Department of Primary Care and Public Health, School of Public Health, Imperial College London, London, UK. ${ }^{5}$ Women \& Child Health Program, GIC, The George Institute for Global Health at Peking University Health Science Center, Beijing, China. ${ }^{6}$ School of Public Health, Chinese Academy of Medical Sciences and Peking Union Medical College, Beijing 100730, China. ${ }^{7}$ Melbourne School of Population and Global Health, The University of Melbourne, Melbourne, Victoria 3010, Australia. ${ }^{8} \mathrm{WHO}$ Collaborating Centre on Implementation Research for Prevention and Control of Noncommunicable Diseases, Melbourne, VIC, Australia.

\section{Received: 23 November 2020 Accepted: 2 June 2021}

Published online: 10 June 2021

\section{References}

1. Guidelines for the management of physical health conditions in adults with severe mental disorders. Geneva: World Health Organization; 2018. http://a pps.who.int/iris/bitstream/handle/10665/275718/9789241550383-eng. pdf?ua=1. Accessed 7 Nov 2018.

2. St-Onge MP, Grandner MA, Brown D, Conroy MB, Jean-Louis G, Coons M, et al. Sleep duration and quality: impact on lifestyle behaviours and cardiometabolic health: a scientific statement from the American Heart Association. Circulation. 2016;134(18):e367-86. https://doi.org/10.1161/CIR. 0000000000000444.

3. Marengoni A, Angleman S, Melis R, Mangialasche F, Karp A, Garmen A, et al. Aging with multimorbidity: a systematic review of the literature. Ageing Res Rev. 2011;10(4):430-9. https://doi.org/10.1016/j.arr.2011.03.003.

4. Garin N, Koyanagi A, Chatterji S, Tyrovolas S, Olaya B, Leonardi M, et al. Global multimorbidity patterns: a cross-sectional, population-based, multi- country study. J Gerontol A Biol Sci Med Sci. 2016;71(2):205-14. https://doi. org/10.1093/gerona/glv128.

5. Gu J, Chao J, Chen W, Xu H, Wu Z, Chen H, et al. Multimorbidity in the community-dwelling elderly in urban China. Arch Gerontol Geriatr. 2017;68: 62-7. https://doi.org/10.1016/j.archger.2016.09.001.

6. Yao SS, Cao GY, Han L, Chen ZS, Huang ZT, Gong P, et al. Prevalence and patterns of multimorbidity in a nationally representative sample of older Chinese: results from the China health and retirement longitudinal study. J Gerontol A Biol Sci Med Sci. 2020;75(10):1974-80. https://doi.org/10.1093/ gerona/glz185.

7. Zhao Y, Zhang P, Oldenburg B, Hall T, Lu S, Haregu TN, et al. The impact of mental and physical multimorbidity on healthcare utilization and health spending in China: a nationwide longitudinal population-based study. Int J Geriatr Psychiatry. 2021;36(4):500-10. https://doi.org/10.1002/gps.5445.

8. Zhao Y, Zhang P, Oldenburg B, Hall T, Lu S, Haregu TN, et al. Multimorbidity and out-of-pocket expenditure on medicines: a systematic review. BMJ Glob Health. 2018;3(1):e000505. https://doi.org/10.1136/bmjgh-2017-000505.

9. Kavalidou K, Smith DJ, Der G, O'Connor RC. The role of physical and mental multimorbidity in suicidal thoughts and behaviours in a Scottish population cohort study. BMC Psychiatry. 2019;19(1):38. https://doi.org/10.1186/s12888019-2032-8.

10. Gould CE, O'Hara R, Goldstein MK, Beaudreau SA. Multimorbidity is associated with anxiety in older adults in the health and retirement study. Int J Geriatr Psychiatry. 2016;31(10):1105-15. https://doi.org/10.1002/gps.4532.

11. Fortin M, Dubois MF, Hudon C, Soubhi H, Almirall J. Multimorbidity and quality of life: a closer look. Health Qual Life Outcomes. 2007;5(1):52. https:// doi.org/10.1186/1477-7525-5-52.

12. Dugravot A, Fayosse A, Dumurgier J, Bouillon K, Rayana TB, Schnitzler A, et al. Social inequalities in multimorbidity, frailty, disability, and transitions to mortality: a 24-year follow-up of the Whitehall II cohort study. Lancet Public Health. 2020;5(1):e42-50. https://doi.org/10.1016/S2468-2667(19)30226-9.

13. Emerging Risk Factors Collaboration, Di Angelantonio E, Kaptoge $\mathrm{S}$, Wormser D, Willeit P, Butterworth AS, et al. Association of cardiometabolic multimorbidity with mortality. JAMA. 2015;314:52-60. https://doi.org/https:// doi.org/10.1001/jama.2015.7008, 1.

14. Chudasama YV, Khunti KK, Zaccardi F, Rowlands AV, Yates T, Gillies CL, et al. Physical activity, multimorbidity, and life expectancy: a UK biobank longitudinal study. BMC Med. 2019;17(1):108. https://doi.org/10.1186/s12916019-1339-0.

15. Dhalwani NN, O'Donovan G, Zaccardi F, Hamer M, Yates T, Davies M, et al. Long terms trends of multimorbidity and association with physical activity in older English population. Int J Behav Nutr Phys Act. 2016;13(1):8. https:// doi.org/10.1186/s12966-016-0330-9.

16. Freisling $H$, Viallon $V$, Lennon $H$, Bagnardi V, Ricci $C$, Butterworth AS, et al. Lifestyle factors and risk of multimorbidity of cancer and cardiometabolic diseases: a multinational cohort study. BMC Med. 2020;18(1):5. https://doi. org/10.1186/s12916-019-1474-7.

17. Jackson CA, Dobson AJ, Tooth LR, Mishra GD. Lifestyle and socioeconomic determinants of multimorbidity patterns among mid-aged women: a longitudinal study. PLoS One. 2016;11(6):e0156804. https://doi.org/10.1371/ journal.pone.0156804.

18. Melis R, Marengoni A, Angleman S, Fratiglioni L. Incidence and predictors of multimorbidity in the elderly: a population-based longitudinal study. PLoS One. 2014;9(7):e103120. https://doi.org/10.1371/journal.pone.0103120.

19. Mounce LTA, Campbell JL, Henley WE, Tejerina Arreal MC, Porter I, Valderas JM. Predicting incident multimorbidity. Ann Fam Med. 2018;16(4):322-9. https://doi.org/10.1370/afm.2271.

20. Singh-Manoux A, Fayosse A, Sabia S, Tabak A, Shipley M, Dugravot A, et al. Clinical, socioeconomic, and behavioral factors at age 50 years and risk of cardiometabolic multimorbidity and mortality: a cohort study. PLoS Med. 2018;15(5):e1002571. https://doi.org/10.1371/journal.pmed.1002571.

21. Xu X, Mishra GD, Dobson AJ, Jones M. Progression of diabetes, heart disease, and stroke multimorbidity in middle-aged women: a 20-year cohort study. PLoS Med. 2018;15(3):e1002516. https://doi.org/10.1371/journal. pmed. 1002516.

22. Wikström K, Lindström J, Harald K, Peltonen M, Laatikainen T. Clinical and lifestyle-related risk factors for incident multimorbidity: 10-year follow-up of Finnish population-based cohorts 1982-2012. Eur J Intern Med. 2015;26(3): 211-6. https://doi.org/10.1016/j.ejim.2015.02.012.

23. Vancampfort D, Koyanagi A, Ward PB, Rosenbaum S, Schuch FB, Mugisha J, et al. Chronic physical conditions, multimorbidity and physical activity 
across 46 low- and middle-income countries. Int J Behav Nutr Phys Act. 2017;14(1):6. https://doi.org/10.1186/s12966-017-0463-5.

24. Fortin M, Haggerty J, Almirall J, Bouhali T, Sasseville M, Lemieux M. Lifestyle factors and multimorbidity: a cross sectional study. BMC Public Health. 2014; 14(1):686. https://doi.org/10.1186/1471-2458-14-686.

25. Dhalwani NN, Zaccardi F, O'Donovan G, Carter P, Hamer M, Yates T, et al. Association between lifestyle factors and the incidence of multimorbidity in an older English population. J Gerontol A Biol Sci Med Sci. 2017;72:528-34. https://doi.org/10.1093/gerona/glw146.

26. Marques A, Santos DA, Peralta M, Sardinha LB, González VM. Regular physical activity eliminates the harmful association of television watching with multimorbidity: a cross-sectional study from the European social survey. Prev Med. 2018;109:28-33. https://doi.org/10.1016/j.ypmed.2018.01.015.

27. Helbig AK, Stöckl D, Heier M, Thorand B, Schulz H, Peters A, et al. Relationship between sleep disturbances and multimorbidity among community-dwelling men and women aged 65-93 years: results from the KORA age study. Sleep Med. 2017;33:151-9. https://doi.org/10.1016/.jsleep.2 017.01.016.

28. Nicholson K, Rodrigues R, Anderson KK, Wilk P, Guaiana G, Stranges S. Sleep behaviours and multimorbidity occurrence in middle-aged and older adults: findings from the Canadian longitudinal study on aging (CLSA). Sleep Med. 2020;75:156-62. https://doi.org/10.1016/j.sleep.2020.07.002.

29. Ruiz-Castell M, Makovski TT, Bocquet V, Stranges S. Sleep duration and multimorbidity in Luxembourg: results from the European health examination survey in Luxembourg, 2013-2015. BMJ Open. 2019;9(8): e026942. https://doi.org/10.1136/bmjopen-2018-026942.

30. Wang $Y M$, Song $M$, Wang $R$, Shi L, He J, Fan TT, et al. Insomnia and multimorbidity in the community elderly in China. J Clin Sleep Med. 2017; 13(04):591-7. https://doi.org/10.5664/jcsm.6550.

31. Kredlow MA, Capozzoli MC, Hearon BA, Calkins AW, Otto MW. The effects of physical activity on sleep: a meta-analytic review. J Behav Med. 2015;38(3): 427-49. https://doi.org/10.1007/s10865-015-9617-6.

32. Xiao Q, Keadle SK, Hollenbeck AR, Matthews CE. Sleep duration and total and cause-specific mortality in a large US cohort: interrelationships with physical activity, sedentary behavior, and body mass index. Am J Epidemiol. 2014;180(10):997-1006. https://doi.org/10.1093/aje/kwu222.

33. Sillars A, Ho FK, Pell GP, Gill JMR, Sattar N, Gray S, et al. Gender differences in the association of risk factors for heart failure incidence and mortality. Heart. 2020;106:203-12. https://doi.org/10.1136/heartjnl-2019-314878.

34. Zhao Y, Hu Y, Smith JP, Strauss J, Yang G. Cohort profile: the China health and retirement longitudinal study (CHARLS). Int J Epidemiol. 2014;43(1):618. https://doi.org/10.1093/ije/dys203.

35. Starfield B, Kinder K. Multimorbidity and its measurement. Health Policy. 2011;103(1):3-8. https://doi.org/10.1016/..healthpol.2011.09.004.

36. Jennings GL, Touyz RM. Hypertension guidelines: more challenges highlighted by Europe. Hypertension. 2013;62(4):660-5. https://doi.org/10.11 61/HYPERTENSIONAHA.113.02034.

37. Xu Y, Wang L, He J, Bi Y, Li M, Wang T, et al. Prevalence and control of diabetes in Chinese adults. JAMA. 2013;310(9):948-59. https://doi.org/10.1 001/jama.2013.168118.

38. Joint committee for guideline revision. 2016 Chinese guidelines for the management of dyslipidemia in adults. J Geriatr Cardiol. 2018;15:1-29. https://doi.org/10.11909/j.issn.1671-5411.2018.01.011.

39. Craig CL, Marshall AL, Sjöström M, Bauman AE, Booth ML, Ainsworth BE, et al. International physical activity questionnaire: 12-country reliability and validity. Med Sci Sports Exerc. 2003;35(8):1381-95. https://doi.org/10.1249/01. MSS.0000078924.61453.FB.

40. The IPAQ Group. Guidelines for data processing and analysis of the International Physical Activity Questionnaire (IPAQ)-Short and Long Forms. 2005. https://docs.google.com/viewer?a=v\&pid=sites\&srcid= ZGVmYXVsdGRvbWFpbnxOaGVpcGFxfGd4OjEONDgxMDk3NDU1YWRIZTM. Accessed 12 Mar 2021.

41. Hirshkowitz M, Whiton K, Albert SM, Alessi C, Bruni O, DonCarlos L, et al. National sleep foundation's updated sleep duration recommendations: final report. Sleep Health. 2015;1(4):233-43. https:// doi.org/10.1016/j.sleh.2015.10.004.

42. Andersen EM, Malmgren JA, Carter WB, Patrick DL. Screening for depression in well older adults: evaluation of a short form of the CES-D. Am J Prev Med. 1994;10:77-84.
43. Boey KW. Cross-validation of a short form of the CES-D in Chinese elderly. Int J Geriatr Psychiatry. 1999;14(8):608-17. https://doi.org/10.1002/(sici)1 099-1166(199908) 14:8<608:aid-gps991>3.0.co;2-z.

44. Farrar DE, Glauber RR. Multicollinearity in regression analysis: the problem revisited. Rev Econ Stat. 1967;49(1):92-107. https://doi.org/10.2307/1937887.

45. Knol MJ, VanderWeele TJ. Recommendations for presenting analyses of effect modification and interaction. Int J Epidemiol. 2012;41(2):514-20. https://doi.org/10.1093/ije/dyr218.

46. Hosmer DW, Lemeshow S. Confidence interval estimation of interaction Epidemiology. 1992;3(5):452-6. https://doi.org/10.1097/00001648-1992 09000-00012.

47. VanderWeele TJ, Knol MJ. A tutorial on interaction. Epidemiol Methods. 2014;3:33-72.

48. Wennman H, Kronholm E, Heinonen O, Kujala U, Kaprio J, Partonen T, et al. Leisure time physical activity and sleep predict mortality in men irrespective of background in competitive sports. Prog Prev Med. 2017;2:pe0009. https:// doi.org/10.1097/pp9.0000000000000009.

49. Kankanhalli A, Saxena M, Wadhwa B. Combined interventions for physical activity, sleep, and diet using smartphone apps: a scoping literature review. Int J Med Inform. 2019;123:54-67. https://doi.org/10.1 016/j.jijmedinf.2018.12.005.

\section{Publisher's Note}

Springer Nature remains neutral with regard to jurisdictional claims in published maps and institutional affiliations.

\section{Ready to submit your research? Choose BMC and benefit from:}

- fast, convenient online submission

- thorough peer review by experienced researchers in your field

- rapid publication on acceptance

- support for research data, including large and complex data types

- gold Open Access which fosters wider collaboration and increased citations

- maximum visibility for your research: over $100 \mathrm{M}$ website views per year

At BMC, research is always in progress.

Learn more biomedcentral.com/submissions 